Proceeding Paper

\title{
Synthesis and Structure of Novel Potentially Bioactive Amphiphilic -O-(N)-Glycosides ${ }^{\dagger}$
}

\author{
Natividad Bejarano, Leticia Lafuente, Juliana Esteche, Cintia C. Santiago, Agustín H. Rojas \\ and Agustín Ponzinibbio *
}

Citation: Bejarano, N.; Lafuente, L.; Esteche, J.; Santiago, C.C.; Rojas, A.H.; Ponzinibbio, A. Synthesis and Structure of Novel Potentially Bioactive Amphiphilic -O-(N)Glycosides. Chem. Proc. 2021, 3, 100. https://doi.org/10.3390/ecsoc-2408286

Academic Editors: Julio A. Seijas and M. Pilar Vázquez-Tato

Published: 14 November 2020

Publisher's Note: MDPI stays neutral with regard to jurisdictional claims in published maps and institutional affiliations.

Copyright: @ 2020 by the authors. Licensee MDPI, Basel, Switzerland. This article is an open access article distributed under the terms and conditions of the Creative Commons Attribution (CC BY) license (http://creativecommons.org/licenses/by/4.0/).

\author{
Centro de Estudio de Compuestos Orgánicos (CEDECOR), Departamento de Química, Facultad de Ciencias \\ Exactas, Universidad Nacional de La Plata, 47 y 115, 1900 La Plata, Argentina; \\ natividadbejarano@quimica.unlp.edu.ar (N.B.); llafuente@quimica.unlp.edu.ar (L.L.); \\ jesteche@exactas.unlp.edu.ar (J.E.); csantiago@quimica.unlp.edu.ar (C.C.S.); \\ ahrojas@quimica.unlp.edu.ar (A.H.R.) \\ * Correspondence: ponzinibbio@quimica.unlp.edu.ar \\ + Presented at the 24th International Electronic Conference on Synthetic Organic Chemistry, \\ 15 November-15 December 2020; Available online: https://ecsoc-24.sciforum.net/.
}

\begin{abstract}
Herein we present the synthesis and structural analysis of novel - $O-(N)$-glycosides. The biphasic reaction of NHS and acetobromo- $\alpha$-D-glucose or D-galactose gives the $\beta$ anomer glycoside in a straightforward manner. Further hydrazinolysis and condensation with decanal afforded the desired products. Their complete structures, including the anomeric and $E / Z$ double bond configurations, were determined by spectroscopic analysis.
\end{abstract}

Keywords: amphiphilic carbohydrates; -O-(N)-glycosides; NMR

\section{Introduction}

Carbohydrate-based surfactants are molecules with a sugar hydrophilic moiety and a hydrophobic tail, usually a hydrocarbon chain such as a fatty acid or alcohol. These glycosides have been synthesized in the last few decades and their structures were analyzed in terms of supramolecular arrangements as described in the literature [1-3]. Furthermore, they were proposed as potential therapeutic active molecules. This bioactive profile it's based on their capability to interact with the lipid bilayer of biological membranes due to the lipophilicity exhibited by the glycoside's aglycone [4]. In this work, we show the design and synthesis of carbohydrate derivatives with amphiphilic properties including a bioactive moiety, a Schiff base. Oxime ether function is an important structural motif in many famous drug scaffolds. Many antiviral agents have the $-\mathrm{C}=\mathrm{N}-\mathrm{O}$ - function in their structures, for example, the kinase inhibitor "enviroxime" and the recently reported "EIDD-2801" glycoside, which has shown broad anti-influenza virus activity [5].

\section{Materials and Methods}

\subsection{General}

Commercially available reagents were directly used without further purification. All sugar derivatives precursors were prepared by known methods, carefully purified, and fully characterized by ${ }^{1} \mathrm{H}$ and ${ }^{13} \mathrm{C}$ NMR. Reactions were monitored by TLC on silica gel (Merck 60 F254 plates), with detection by UV light $(254 \mathrm{~nm})$ or by charring with sulfuric acid. Flash chromatography was performed using silica gel (230-400 mesh). ${ }^{1} \mathrm{H}$ and ${ }^{13} \mathrm{C}$ NMR spectra were recorded on a Bruker AVIII (600 and $150 \mathrm{MHz}$, respectively) in $\mathrm{CDCl}_{3}$. HSQC and COSY spectra were used to establish peak assignments in ${ }^{1} \mathrm{H}$ and ${ }^{13} \mathrm{C}$ NMR. 


\subsection{N-Hydroxysuccinimide Glycosylation}

To a stirred mixture of acetobromo- $\alpha$-D-glucose $(1 \mathrm{mmol})$ and $\mathrm{Na}_{2} \mathrm{CO}_{3}$ solution in $\mathrm{CH}_{2} \mathrm{Cl}_{2}(10 \mathrm{~mL}, 1 \mathrm{M})$ was added $\mathrm{N}$-hydroxysuccinimide $(3 \mathrm{mmol})$ followed by TBAHS (1 mmol) phase transfer catalyst. The mixture was stirred at $25^{\circ} \mathrm{C}$ until the reaction was completed as indicated by TLC. Then, $\mathrm{CH}_{2} \mathrm{Cl}_{2}(10 \mathrm{~mL})$ was added and washed twice with $10 \mathrm{~mL}$ of water and brine. The organic layer was dried and concentrated in vacuo. The corresponding product was purified by flash column chromatography to obtain the pure glycoside derivative.

\subsection{Hydrazinolysis Procedure}

To a stirred solution of the aforementioned compound $(0.5 \mathrm{mmol})$ in $10 \mathrm{~mL}$ of $1: 1$ $\mathrm{CH}_{2} \mathrm{Cl}_{2}-\mathrm{MeOH}$ mixture was added hydrazine hydrate $(1.5 \mathrm{mmol})$ at room temperature. The reaction was monitored by TLC, and after 30 min quenched with $5 \mathrm{~mL}$ of saturated $\mathrm{NaHCO}_{3}$ solution. The mixture was extracted with $3 \times 10 \mathrm{~mL}$ of $\mathrm{CH}_{2} \mathrm{Cl}_{2}$. The organic layers were washed with brine, dried, and concentrated in vacuo. Products 1 (D-glucose derivative) and $\mathbf{2}$ (D-galactose derivative) were carefully purified by column chromatography to obtain the corresponding $-\mathrm{O}-\mathrm{NH}_{2} \beta$-glycoside.

\subsection{Synthesis of Oxime Derivatives}

The aminooxygycoside $(1 \mathrm{mmol})$ and $1.2 \mathrm{eq}$ of decanal were dissolved in dried $\mathrm{CH}_{2} \mathrm{Cl}_{2}(2 \mathrm{~mL})$ then one drop of concentrated $\mathrm{HCl}$ was added. The mixture was stirred for $24 \mathrm{~h}$ at ambient temperature until the reaction was completed as indicated by TLC, then quenched with water $(3 \mathrm{~mL})$ and the aqueous phase was extracted with $\mathrm{CH}_{2} \mathrm{Cl}_{2}(3 \times 10$ $\mathrm{mL}$ ), neutralized with $\mathrm{NaHCO}_{3}$ solution and washed twice with water. The combined organic layers were dried and concentrated under reduced pressure. The residue was dried under high vacuum. The purification was performed by flash column chromatography (hexane/EtOAc 8:2) to afford the desired compounds 3 and 4.

\section{Results and Discussion}

The biphasic reaction between $N$-hydroxysuccinimide and acetobromo- $\alpha$-D-glucose or D-galactose gives the $\beta$-O-(N)-glycoside in a straightforward manner. Further hydrazinolysis and condensation with decanal, under acid catalysis, give the desired products. (Figure 1)<smiles>CC(=O)OCC1OC(Br)C(OC(C)=O)C(OC(C)=O)C1OC(C)=O</smiles>
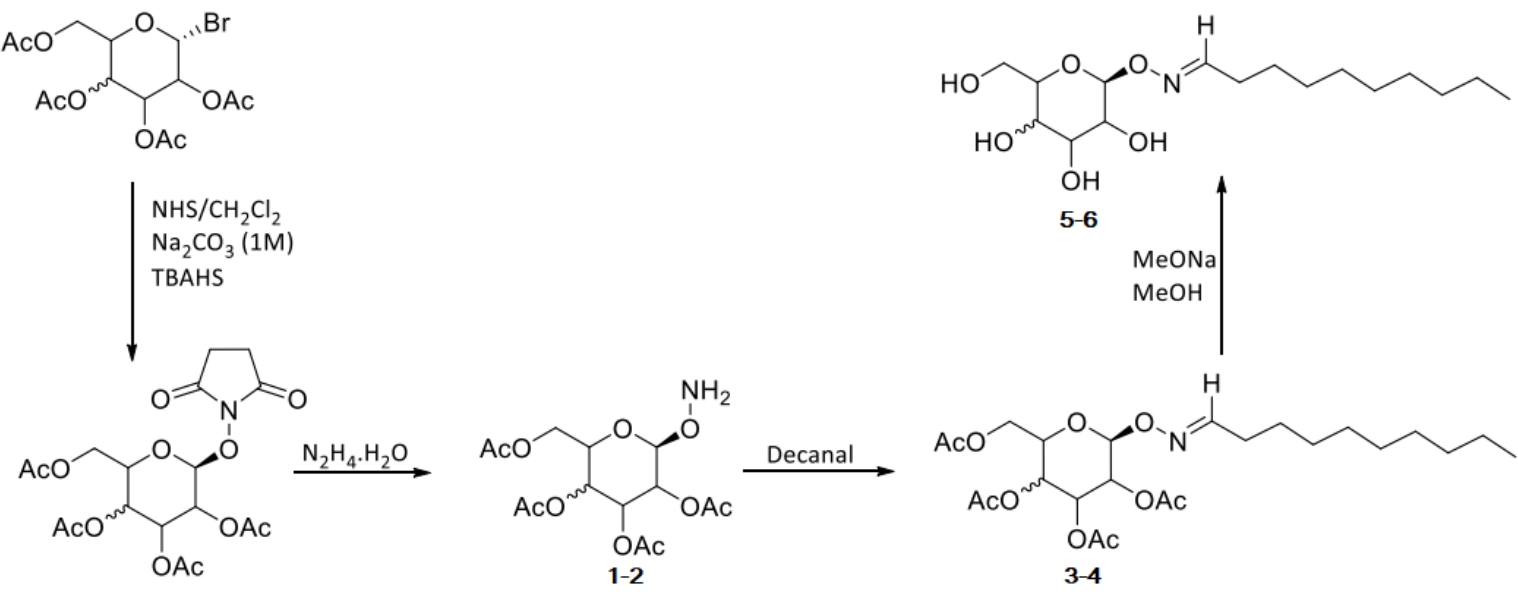

Figure 1. Multistep synthesis of amphiphilic glycosides Schiff bases from acetobromo- $\alpha$-D-glucose and D-galactose.

In all cases, we obtained the products in good yields and high anomeric stereoselectivity. The values of the ${ }^{3} \mathrm{~J} 1-\mathrm{H} 2$ coupling constants were measured and all of them were around 8-9 Hz. This undoubtedly indicates the beta configuration at the anomeric center. 
Their structures were determined and fully characterized by ${ }^{1} \mathrm{H}$ and ${ }^{13} \mathrm{C}$ NMR spectroscopy and were as expected. The oxime ether glycosidic linkage is a Schiff base moiety. The $E$ isomer is the thermodynamically more stable and consequently the major isomer obtained. ${ }^{1} \mathrm{H}$ NMR spectra of nonpurified products reveal the presence of a minor byproduct. An isomeric compound was detected in a 3:2 ratio in both the D-glucose and D-galactose derivatives. Particularly, the oximyl proton could be clearly differentiated, and we present $\delta$ values obtained in Table 1 .

Table 1. Oximyl proton displacements for compounds 3 and 4 , the values were extracted from ${ }^{1} \mathrm{H}$ NMR spectra of isomeric mixtures.

\begin{tabular}{ccc}
\hline Product & $\boldsymbol{\delta 1} \mathbf{( \mathbf { p p m } )}$ & $\boldsymbol{\delta 2}(\mathbf{p p m})$ \\
\hline $\mathbf{3}$ & 6.81 & 7.51 \\
$\mathbf{4}$ & 6.80 & 7.53 \\
\hline
\end{tabular}

The complete ${ }^{1} \mathrm{H}$ and ${ }^{13} \mathrm{C}$ NMR experiments demonstrate that this minor product was the $Z$ isomer. The assignment of the $E / Z$ configuration may be done from the ${ }^{1} \mathrm{H}$ NMR spectra of the oxime protons. It is well reported that the oximyl protons of $(E)$-oxime ethers are deshielded relative to those of (Z)-oxime ethers [6].

After flash column chromatography with 15-25 $\mu \mathrm{m}$ silica gel, it was possible to separate both isomers. Pure $E$ and $Z$ products were obtained and the NMR analysis confirms ours mentioned hypothesis. Comparing the data extracted from ${ }^{1} \mathrm{H}$ NMR spectra, with those reported previously by us and others we may consider that the $E$ configuration isomer was the major product obtained [7] (Figure 2).

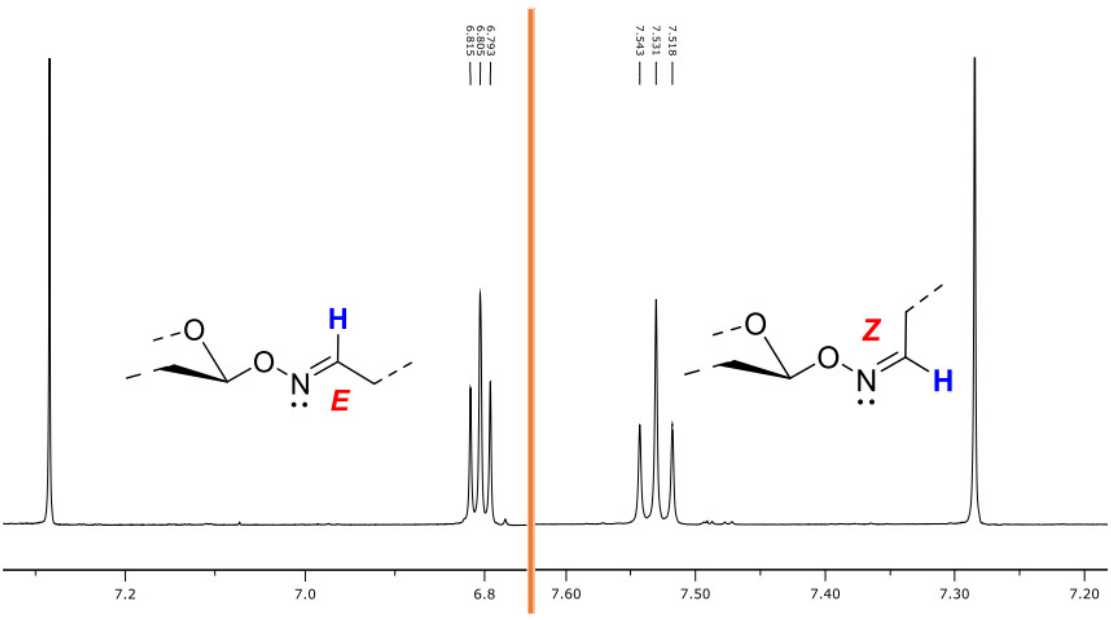

Figure 2. Partial ${ }^{1} \mathrm{H}$ NMR spectra for both $E$ and $Z$ isomers of $\mathbf{3 a}$ and $\mathbf{3 b}$.

With the method optimized, after Zemplén deacetylation we synthesized four new $\mathrm{O}-(\mathrm{N})$-glycosides bearing a hydrophobic tail at the anomeric position as seen in Figure 3 [8].<smiles>CCCCCCCC/C=N/OC1O[C@H](CO)[C@@H](O)[C@H](O)[C@H]1O</smiles><smiles>CCCCCCCC/C=N/OC1O[C@H](CO)[C@@H](O)[C@H](O)[C@H]1O</smiles><smiles>CCCCCCCC/C=N/OC1O[C@H](CO)[C@@H](O)[C@H](O)[C@H]1O</smiles><smiles>CCCCCCCC/C=N/OC1O[C@H](CO)[C@@H](O)[C@H](O)[C@H]1O</smiles>

Figure 3. New amphiphilic -O-(N)- $\beta$-glycosides. Overall yields in brackets. 
The glycosides synthetized were particularly stable. As previously described in the literature [9], the stability towards hydrolysis of the oximes is higher than simple hydrazones because of the electronegativity differences in the heteroatom ( $\left.\chi_{\mathrm{O}}=4.5 \mathrm{vs} . \chi_{\mathrm{N}}=3.0\right)$. No acetal or oxime hydrolysis products were detected after several days in the aqueous solution. Moreover, the protonation of the anomeric oxygen, to catalyze the acetal hydrolysis in an exocyclic cleavage, is also not favored. If an alternative endocyclic cleavage mechanism may be performed, the rate-limiting step involves the delocalization of the electrons on oxygen over the glycosidic bond. This delocalization is completely disfavored [10].

\section{Conclusions}

A simple and efficient route for the synthesis of novel amphiphilic carbohydrate-derived oxime ethers has been described. The products were obtained in good overall yields and with high anomeric and $E / Z$ stereocontrol. Both the $E$ and $Z$ isomers were obtained pure after careful chromatography work and a complete structural analysis was done, compiling interesting data that may be used for setting future correlations. We recently initiated investigations to evaluate the surfactant properties and cytotoxic effects of the novel compounds prepared.

Funding: This research received no external funding.

\section{References}

1. Allen, D.K.; Tao, B.Y. Carbohydrate-alkyl ester derivatives as biosurfactants. J. Surfactants Deterg. 1999, 2, 383-390.

2. Söderman, O.; Johansson, J. Polyhydroxyl-based surfactants and their physico-chemical properties and applications. Curr. Opin. Colloid Interface Sci. 1999, 4, 391-401.

3. Ewan, H.S.; Muli, C.S.; Touba, S.; Bellinghiere, A.T.; Veitschegger, A.M.; Smith, T.B.; Pistel, W.L.; Jewell, W.T.; Rowe, R.K.; Hagen, J.P.; et al. Synthesis of sugar oxime ether surfactants. Tetrahedron Lett. 2014, 55, 4962-4965.

4. Xavier, N.M.; Rauter, A.P. Environmentally friendly approaches to the synthesis of new antibiotics from sugars. Pure Appl. Chem. 2012, 84, 803-816.

5. a) Heinz, B.A.; Vance, L.M. The antiviral compound enviroxime targets the 3A coding region of rhinovirus and poliovirus. J. Virol. 1995, 69, 4189-4197. b) Toots, M.; Yoon, J.; Cox, R.M.; Hart, M.; Sticher, M.Z.; Makhsous, N.; Plesker, R.; Barrena, A.H.; Reddy, P.G.; Mitchell, D.G.; et al. Characterization of orally efficacious influenza drug with high resistance barrier in ferrets and human airway epithelia. Sci. Transl. Med. 2019, 11, eaax5866.

6. a) Karabatsos, G.J.; His, N. Structural studies by nuclear magnetic resonance-XI: Conformations and configurations of oxime o-methyl ethers. Tetrahedron 1967, 23, 1079-1095. b) Rodriguez, E.C.; Winans, K.A.; King, D.S.; Bertozzi, C.R. A Strategy for the Chemoselective Synthesis of O-Linked Glycopeptides with Native Sugar-Peptide Linkages. J. Am. Chem. Soc. 1997, 119, 99059906. c) Winans, K.A.; Bertozzi, C.R. An inhibitor of the human UDP-GlcNAc 4-epimerase identified from a uridine-based library: A strategy to inhibit O-linked glycosylation. Chem. Biol. 2002, 9, 113-129.

7. a) Lafuente, L.; Santiago, C.C.; Rojas, A.H.; Piro, O.E.; Echeverría, G.A.; Ponzinibbio, A. Selective Synthesis and Molecular Structure of Novel Aminooxyglycosyl Derivatives Bearing Hydroxyphenyl Moieties. ChemistrySelect 2020, 5, 864-868. b) Lafuente, L.; Rojas, A.H.; Piro, O.E.; Echeverría, G.A.; Ponzinibbio, A.; Synthesis, NMR and X-ray studies on novel heteroaromatic aldoxime O-ether 2-and 2, 3-unsaturated glycosides. Tetrahedron Lett. 2020, 61, 152241.

8. Representative NMR data. Compound 4a. ${ }^{1} \mathrm{H}: \delta 7.53(\mathrm{t}, \mathrm{J}=6.3 \mathrm{~Hz}, 1 \mathrm{H}, \mathrm{H7}) ; 5.43$ (dd, J =3.4, 1.1 Hz, 1H, H4); 5.32 (dd, J =10.4, 8.4 $\mathrm{Hz}, 1 \mathrm{H}, \mathrm{H} 2) ; 5.15$ (d, J =8.45 Hz, 1H, H1); 5.10 (dd, J =10.35, 3.4 Hz, 1H, H3); 4.20 (d, J =6.8 Hz, 2H, H6); 4.03 (td, J =6.84, 1.20 Hz, 1H, H5); 2.24-1.27 (m, 16H, H 8-15); 2.17 (s, 3H, CH3); 2.08 (s, 3H, CH3); 2.06 (s, 3H, CH3); 2.01 (s, 3H, CH3); 0.90 (t, 3H, H16). ${ }^{13} \mathrm{C}$ : 170.35 (C=O); 170.28 (C=O); $170.14(\mathrm{C}=\mathrm{O}) ; 169.50(\mathrm{C}=\mathrm{O}) ; 155.11$ (C7); 102.35 (C1); 71.15 (C3); 70.71 (C5); 67.54 (C2); 66.86 (C4); 61.01 (C6); 31.90-22.66 ( $\left.\mathrm{CH}_{2}\right) ; 20.80-20.59\left(\mathrm{CH}_{3}\right) ; 14.11(\mathrm{C} 16)$.

9. Pifferi, C.; Daskhan, G.C.; Fiore, M.; Shiao, T.C.; Roy, R.; Renaudet, O. Aminooxylated carbohydrates: Synthesis and applications. Chem. Rev. 2017, 117, 9839-9873.

10. Kalia, J.; Raines, R.T. Hydrolytic stability of hydrazones and oximes. Angew. Chem. Int. Ed. 2008, 47, 7523-7526. 